\title{
AFETO E ADOECIMENTO DO CORPO: CONSIDERAÇÕES PSICANALÍTICAS
}

Monah Winograd e Leônia Cavalcanti Teixeira

Monah Winograd

Psicanalista, doutora em Teoria

Psicanalítica (IP/

UFRJ). Professora

assistente do

Programa de

Pós-graduação em

Psicologia Clínica da

PUC-Rio

Leônia Cavalcanti

Teixeira

Psicóloga e

psicanalista,

doutora em Saúde

Coletiva (IMS/

Uerj). Professora

titular do Mestrado

em Psicologia da

Universidade de

Fortaleza (Unifor)
RESUMO: Tema de interesse para a clínica, a investigação das psicopatologias somáticas exige reelaborações metapsicológicas que contemplem os lugares do corpo e do afeto. Com a ênfase da psicanálise no recalque, a problemática do afeto teria ficado em segundo plano, causando uma lacuna comprometedora dos rumos dos atos clínicos. Resgatar as elaborações freudianas sobre o afeto, especialmente sua supressão, pode abrir espaço para a escuta da dor dos corpos enfermos. Neste ensaio, investigamos inicialmente a metapsicologia freudiana do afeto para, em seguida, propor elaborações a respeito dos destinos do corpo nas formações psicossomáticas.

Palavras-chave: Corpo, afeto, psicanálise, sofrimento psíquico, psicossomática.

ABSTRACT: Affect and body illness: psychoanalytical considerations. Topic of interest for the clinic, the research of somatic psychopathologies requires metapsychological reelaborations that consider the place of the Body and the Affect. With the emphasis on the repression, the problematic of the Affect would have stayed in the background, causing a compromising gap on the course of the clinical acts. Retrieving Freudian elaborations on the Affect, especially its suppression, can open space for the listening to the pain of sick bodies. In this essay, we have first investigated the Freudian metapsychology of the Affect for, then, propose elaborations about the destinies of the Body in psychosomatic formations

Keywords: Body, affect, psychoanalysis, psychic suffering, psychosomatic 


\section{INTRODUÇÃO}

As formas de mal-estar psíquico da atualidade exigem a revisão de pressupostos e de conceitos que guiam as diferentes perspectivas no lidar com o psíquico e seus destinos. Assim, pensamos serem fundamentais a apresentação e a discussão dos modos como nos situamos frente aos sofrimentos típicos da atualidade, particularmente quando o corpo se torna a expressão principal das vicissitudes do pathos (BERLINCK, 2000; FEDIDA, 2001). Os fenômenos psicossomáticos constituem parte significativa da clínica contemporânea, demonstrando como o corpo pode se tornar lugar privilegiado do sofrimento. Considerando concepções da psicossomática sobre a doença orgânica e os questionamentos oriundos deste campo teórico (ÁVILA, 2002; DEJOURS, 1994; NASIO, 1997 e 2000), investigamos algumas leituras dos fenômenos psicossomáticos. As elaborações teóricas e clínicas aqui expostas supõem a articulação entre sofrimento, cultura e subjetividade (BIRMAN, 1999 e 2006; COSTA, 2004). Tendo em vista o problema dos lugares do corpo na psicanálise e, especialmente, as formas pelas quais a doença orgânica se faz presente nas construções clínicas e metapsicológicas de Freud, destacamos a questão do afeto e suas vicissitudes. Assim, a primeira parte do texto se dedica a investigar a construção da noção de afeto em Freud para, em seguida, tematizar algumas concepções da manifestação psicossomática derivadas das ideias de Freud.

\section{O AFETO EM FREUD: ENTRE O CORPO E O PSIQUISMO}

“"Se eu nos sonhos sinto medo de uns ladrões, os ladrões são por certo imaginários, mas o medo é real, e ocorre o mesmo quando me regozijo nos sonhos" (FREUD, 1900/1976, p.458). Prestar atenção nos afetos parecia a Freud ser um bom caminho para entender a natureza da alma humana. Para compreender um sonho, por exemplo, ele seguia os afetos nas séries de representações. O mesmo acontecia nos encontros com seus pacientes: as variações afetivas, das paixões intensas às hostilidades ao psicanalista e ao tratamento em geral, indicavam-lhe que direção dar ao tratamento. Às vezes, tudo acontecia tão rápido que não era possível intervir, como no caso de uma senhora (1914/1976) que, ao cabo de uma semana na qual a transferência aumentou demais, evadiu-se de Freud como fazia repetidamente com seu marido. Outras vezes, era preciso esperar e, sem tomar as hostilidades do paciente como pessoais, consentir num decurso que não podia ser evitado nem apurado de imediato. As resistências precisavam de tempo para a sua reelaboração, a qual constituía a peça do trabalho produtora do efeito alterador máximo sobre o paciente e que distingue o tratamento analítico de toda influência sugestiva (FREUD, 1914/1976). 
Apesar da importância do afeto para a teoria psicanalítica, Freud nunca fez uma definição, nem dedicou mais do que poucos parágrafos de alguns textos para esclarecer como pensava sua natureza e origem. O fato de Freud nunca ter sistematizado o que entendia por afeto, como fez, por exemplo, com o conceito de representação, deixou aberto o caminho para uma discussão técnica sobre seu estatuto teórico. Laplanche \& Pontalis (1986) e Green (1997), por exemplo, veem dificuldades no estabelecimento do conceito de afeto em Freud, preferindo categorizá-lo como noção. Já Reys (1998) acredita que, dentre todos os termos empregados por Freud — afetos, emoções ou sentimentos —, o afeto é o único que poderia ser considerado um conceito, seja pela quantidade de vezes em que é empregado, pelo número de termos correlatos ou derivados, ou em virtude do contexto em que aparece.

Logo no começo de suas reflexões sobre as neuroses, Freud (1894/1976) equacionou os afetos com uma quantidade em operação no psiquismo. A expressão "quantum" ou "cota de afeto (Affektbetrag)" era utilizada para designar uma intensidade psíquica — correlata das quantidades de excitação somática — capaz de se descolar da representação à qual estaria originalmente ligada, tendo destinos variados. Em 1894, numa célebre passagem de As neuropsicoses de defesa, Freud (1894/1976) sugere que é preciso distinguir, nas funções psíquicas,

"algo (cota de afeto, soma de excitação) que tem todas as propriedades de uma quantidade - ainda que não tenhamos meio algum para medi-la —; algo que é suscetível de aumento, diminuição, deslocamento e descarga, e se difunde pelas vias mnêmicas das representações como o faria uma carga elétrica pela superfície dos corpos." (p.6)

A ideia geral era que cada impressão psíquica estaria provida de certo valor afetivo, já que em todo indivíduo existiria a tendência a reduzir esta quantidade ao nível mínimo necessário para seu funcionamento psíquico. O psiquismo reagiria por via motora no sentido da descarga da quantidade recebida, dependendo disto o quanto restaria da intensidade da impressão psíquica recebida. Freud (1894/1976) considerava adequada a reação que descarregasse a mesma quantidade recebida e descreveu três modalidades gerais de descarga: o processamento motor, o processamento por palavras ou o processamento associativo. Na formação do sintoma neurótico, podem-se encontrar dois mecanismos: 1) a descarga do quantum de afeto teria sido suspensa e este teria se fixado numa representação diferente da qual estaria originalmente ligado, tornando esta nova representação patógena devido a uma intensidade excessiva e inadequada; ou 2) o quantum de afeto seria escoado para as inervações somáticas, produzindo alterações no funcionamento corporal usual. De maneira correspondente, na ab- 
reação, a descarga em palavras do quantum de afeto "estrangulado" drenava-o do psiquismo ao redirecioná-lo para a representação à qual estaria originalmente ligado, permitindo seu desgaste (FREUD, 1893/1976).

Nesta época, Freud identificava uma quantidade em operação no psiquismo, observando a variação desta quantidade para maior ou menor intensidade, o deslocamento desta quantidade nas representações ou em direção ao corpo e a descarga. Quantidade, variação, movimento (deslocamento) e descarga: elementos sem os quais não era possível compreender os afetos, mas que não bastavam para sua compreensão. Era preciso explicar como os afetos se transformavam, como o prazer virava desprazer, por exemplo, nos sintomas e nos sonhos penosos. Em 1900, Freud dá mais um passo que só será desenvolvido de modo mais aprofundado quinze anos depois:

“Não podemos prosseguir nossa elucidação se não considerarmos o papel dos afetos nestes processos, o qual, porém, só é possível aqui de maneira incompleta. Formulemos então este enunciado: A sufocação do Ics se torna necessária, sobretudo, porque o decurso das representações no interior do Ics, deixado a si mesmo, desenvolveria um afeto que, em sua origem, teve a característica do prazer, mas, desde que se produziu o processo de repressão, leva a característica do desprazer. A sufocação tem o fim, mas também o resultado, de prevenir esse desenvolvimento de desprazer. (...). Na base disto, há uma suposição muito determinada sobre a natureza do desenvolvimento de afeto. Este é visto como uma operação motriz ou secretória, a chave de cuja inervação se situa nas representações do Ics. Em virtude do governo que exerce o Pré-Cs, estas representações são, por assim dizer, ocluídas, inibidas quanto ao envio dos impulsos que desenvolveriam afeto.” (FREUD, 1900/1976, p.573)

O modelo de aparato psíquico com o qual Freud (1900/1976) trabalhava nesta época, mais conhecido como 'esquema pente', não permitia uma localização tópica do afeto. Composto por sistemas mnêmicos (Inconsciente, Pré-consciente e Consciente) com fronteiras bem definidas, dizia respeito sobretudo às representações, embora fosse possível supor uma 'energia psíquica' transitando pelos sistemas e investindo ora um grupo de representações, ora outro. Os afetos pareciam referir-se ao modo como uma representação que tivesse chegado ao sistema consciente (vinda do interior do aparato ou tendo se formado a partir da percepção) afetava o indivíduo, causando prazer ou desprazer. Ou seja, Freud (1900/1976) identificava um aspecto qualitativo nos afetos e entendia como necessária a participação da consciência.

Contudo, seriam necessários ainda alguns anos para que o metapsicólogo (1916-17/1976) pudesse formular que um afeto inclui, primeiramente, a par- 
ticipação de determinadas inervações motoras ou de descargas, e, em segundo lugar, sensações de duas classes: as percepções das ações motoras ocorridas e as sensações diretas de prazer e desprazer que dão ao afeto sua tonalidade, seu colorido dominante. Ou seja, para Freud (1916-17/1976), o afeto é um processo em ato e em movimento que implica: 1) um aumento da tensão psíquica; 2) o percurso desta tensão dentro do psiquismo; 3 ) um modo específico de descarga dirigida para o interior do corpo; 4) a percepção desta descarga; e 5) as sensações ligadas a ela segundo a matriz prazer-desprazer. Ou seja, o afeto inclui o que acontece ao indivíduo e o modo como ele percebe e entende o que lhe acontece. A percepção da descarga e as sensações de prazer ou desprazer são imediatamente apreendidas na rede de representações que compõe o pré-consciente e o consciente. O afeto é variação corporal e psíquica, bem como a apreensão desta variação pela consciência num movimento reflexivo. Em resumo, para Freud (1916-17/1976), a quantidade de energia e a descarga são elementos do afeto; os outros são as percepções e as sensações que afetam o indivíduo de um modo ou de outro, tenha ele consciência de suas causas ou não. Por exemplo, nos tempos da ab-reação e da catarse, o objetivo do tratamento era justamente fazer o indivíduo referir o quantum de afeto à lembrança do evento traumático. Ou seja, referir o incremento da quantidade de excitação às suas causas e, por aí mesmo, permitir que o indivíduo experimentasse o afeto que a lembrança do trauma gerava em toda a sua intensidade.

Então, podemos entender que, se o quantum de afeto designa uma quantidade de energia que se difunde pelas vias mnêmicas, o afeto propriamente dito inclui este quantum sem reduzir-se a ele. Confundindo afeto e quantum de afeto, Assoun (1997) associa o primeiro a um "gasto" energético das variações na vida psíquica, a um "resto da representação". Assoun (1997), na esteira de Green (1997), propõe que o afeto seja pensado como sendo da ordem do acontecimento: "há afeto quando se passa alguma coisa na vida psíquica” (p.392). Vindo da sensibilidade, o afeto coloca a dinâmica psíquica em movimento. Por si só a definição já seria vaga, mas Assoun (idem) vai adiante e reduz o acontecimento ao seu elemento quantitativo, mais especificamente à descarga: a cota ou o quantum de afeto corresponderia à expressão da pulsão enquanto destacada da representação. Porém, o autor esclarece que seria mais adequado dizer que o afeto é “(...) a subjetivação da pulsão da qual se retirou a 'representação"' (ASSOUN, 1997, p.393): daí o afeto ser sempre 'sentido'. Mas, se o afeto é sentido por um sujeito, então há necessariamente representações envolvidas, ainda que tais representações sejam as de um mal-estar mais ou menos difuso ou as das variações corporais envolvidas, como por exemplo no caso da angústia acompanhada de taquicardia ou sudorese. Com efeito, para Freud, o afeto é variação: inclui a quantidade e a descarga desta quantidade, mas inclui também necessariamente a consciência, 
mesmo confusa, de ambas. Por isso, a referência aos “afetos inconscientes” é apenas uma maneira de falar a posteriori de uma moção que foi inibida em seu desenvolvimento (FREUD, 1915a e b/1976).

Quando, em 1915, Freud fala dos modos pelos quais a pulsão é representada psiquicamente, ele identifica o quantum de afeto e a representação, mas em momento algum reduz o afeto a este quantum. O afeto propriamente dito é um complexo que só se realiza quando há percepção, sensação e ligação do quantum a uma representação consciente. No recalque, produzir-se-ia um divórcio entre o quantum de afeto e a representação, ambos sofrendo destinos diversos. Do ponto de vista descritivo, isto é indiscutível. Porém, para Freud (1915b/1976), o processo real seria, em geral, um quantum de afeto não se fazer notar até que uma nova sub-rogação (Vertretung) irrompa no sistema Cs. Daí ser um abuso conceitual falar que um afeto foi recalcado. Seria mais correto dizer que foi alvo de uma repressão (Unterdrückung), de uma inibição em seu desenvolvimento. Após o recalque, a representação continua existindo no inconsciente como uma "formação real”, mas o afeto corresponde apenas a uma "possibilidade de rudimento à qual não foi permitido desenrolar-se” (FREUD, 1915a/1976, p.174). O objetivo do recalcamento é justo o de inibir a transposição de uma moção pulsional numa exteriorização de afeto necessariamente operada pelo sistema consciente.

Variação quantitativa, movimento, descarga, percepções, sensações e representações são os elementos que, em conjunto, e somente em conjunto, compõem os afetos. Ainda que, por vezes, Freud destaque um ou outro destes elementos, para ele o afeto se dá na conjunção de todos. Por isso, como sugere Green (1997), pode-se considerar o afeto em Freud um termo categorial que agrupa todos os aspectos subjetivos qualificativos da vida emocional em sentido amplo, compreendendo todas as nuanças que a língua alemã (Empfindung, Gefühl) encontra sob este tópico. Daí alguns autores, como Otto Kernberg (1995), preferirem definir o afeto como um padrão psicofisiológico biologicamente determinado e desenvolvimentalmente ativado, portador de um julgamento cognitivo específico, um padrão facial também específico, uma experiência subjetiva de natureza prazerosa ou dolorosa, bem como um padrão de descarga muscular e neurovegetativa. Não fosse a ênfase excessiva na determinação biológica, esta definição seria tão correta do ponto de vista freudiano quanto a de Green (1997).

Mas, se era claro para Freud que os afetos são variações quantitativas e qualitativas, sua natureza e sua origem não pareciam tão evidentes. As indicações que ele tinha sobre o assunto vinham da teoria da evolução de Darwin, aprendida ainda nos tempos de faculdade. Não por acaso, o pai da teoria da evolução é citado nominalmente na parte dos Estudos dedicada ao caso de Elizabeth R. (FREUD, 1893-95/1976). Ali, Freud desenvolve um ponto de vista que permanecerá o 
mesmo até o fim de sua obra, ainda que sua articulação com os outros aspectos envolvidos nos afetos não seja esclarecida:

\begin{abstract}
"Mas eu sustento que o fato de que a histérica crie, mediante simbolização, uma expressão somática para a representação de colorido afetivo é menos individual e arbitrário do que se suporia. Ao tomar literalmente a expressão linguística, ao sentir a 'punhalada no coração' ou a 'bofetada' após um comentário depreciativo como um episódio real, ela não toma liberdade com as palavras, mas torna a animar as sensações às quais a expressão linguística deve sua justificação. (...) Todas estas sensações e inervações pertencem à 'expressão das emoções', que, como nos ensinou Darwin, consiste em operações em sua origem providas de sentido e de acordo a um fim; por mais que hoje se encontrem, na maioria dos casos, debilitadas a tal ponto que sua expressão linguística nos pareça uma transferência figurada, é muito provável que tudo isso fosse compreendido literalmente, e a histeria acerta quando restabelece para suas inervações mais intensas o sentido originário da palavra." (FREUD, 1893-95/1976, p.193)
\end{abstract}

Esta passagem encerra uma das discussões de caso feita por Freud (189395/1976) e ele não retorna ao assunto para maiores esclarecimentos. Ao mesmo tempo em que parece referir-se à fisiologia da expressão dos afetos, aparece o problema da origem da linguagem misturado à ideia de que a ontogenia repete a filogenia. Apenas uma coisa fica mais ou menos clara: a hipótese de que as sensações e inervações dos afetos, bem como sua expressão linguística, são menos individuais e arbitrárias do que se supõe. Ou seja, haveria algo que determina as semelhanças no modo como os indivíduos sentem e expressam, corporal e linguisticamente, os afetos.

Esta ideia foi desenvolvida em tom de brincadeira no rascunho enviado para Ferenczi em 1915, no qual Freud (1915d/1976) relacionou onto e filogênese. Ali, ele esboçou o esquema de um estudo comparativo dos fatores individuais (recalque, contrainvestimento, formação substitutiva e de sintoma, relação à função sexual, regressão, disposição) na histeria de angústia, de conversão e neurose obsessiva. Ao apresentar os fatores disposicionais, o metapsicólogo deu à filogenia lugar de destaque. A hipótese geral era que a regressão e a fixação da libido em cada neurose produzem organizações psíquicas que reproduzem, mais ou menos, fases da história da humanidade do ponto de vista de sua organização anímica. Freud (1915d/1976) organizou as psiconeuroses (não apenas as neuroses de transferência) em uma série de acordo com o ponto no tempo no qual elas aparecem costumeiramente na vida do indivíduo: histeria de angústia, histeria 
de conversão, neurose obsessiva, demência precoce, paranoia, melancolia-mania, bem como as neuroses atuais. ${ }^{1}$

As disposições para a fixação da libido nestas afecções produziriam uma série que vai na direção oposta: quanto mais tarde a neurose aparece, mais antiga é a fase da libido para a qual deve regredir, tanto em termos ontogenéticos quanto filogenéticos. Neste texto, o metapsicólogo (FREUD,1915d/1976) dá ao conceito de regressão - segundo o qual, nas neuroses, a libido retrocederia até um ponto de fixação em seu desenvolvimento ou no desenvolvimento do eu — lugar de destaque. Para ele, o problema da regressão encobriria os problemas da fixação e da disposição, revelando-se como o elemento mais influente na decisão sobre a escolha de neurose. Sua hipótese seria a da possibilidade da fixação ser congênita, produzida por impressões precoces ou ambas, de acordo com cada caso: “Trata-se, portanto, de um pouco mais disso ou daquilo, além de um encontro mais eficaz" (FREUD, 1915d/1976, p.10). Mas o autor esclarece que considerar o elemento constitucional de fixação não afasta a consideração do elemento adquirido, apenas envolve o deslocamento da investigação para um passado ainda mais remoto, pois o herdado seria o que resta do que foi adquirido um dia ao longo da história da humanidade. Vê-se como, das questões envolvendo a disposição ontogenética, Freud (1915d/1976) chega ao problema complexo da disposição filogenética. Esta mesma problemática aparece de passagem também em outros escritos da mesma época. Em A pulsão e suas vicissitudes (1915c/1976), Freud escreve que “(...) nada nos impede esta conjectura: as próprias pulsões, ao menos em parte, são precipitados dos efeitos de estímulos externos que, no curso da filogênese, influenciaram a substância viva, modificando-a" (p.116). Ou ainda, em 1918, ao encerrar suas elaborações sobre o caso do Homem dos Lobos, Freud (1918/1976) sublinha dois problemas que o capturaram particularmente. Um deles era o dos esquemas que a criança traz consigo ao nascer e que ele supõe serem filogenéticos, ou seja, precipitados da história da civilização humana. Dentre tais esquemas, o metapsicólogo destaca o complexo de Édipo como sendo o mais conhecido e adianta a hipótese de que considerar as contradições entre as vivências relativamente aos esquemas enriqueceria o entendimento dos conflitos infantis e, portanto, da escolha de neurose.

Evidentemente, como assinala Perron (2005), tais posições freudianas são complexas e criticáveis por vários motivos, desde certa assimilação do homem pré-histórico à criança, passando por sua inspiração em um darwinismo social cujas consequências são no mínimo discutíveis, até a utilização da hipótese

\footnotetext{
${ }^{1}$ Em relação às neuroses atuais, Freud (1895a/1976, 1898/1976, 1917/1976) desenvolveu aspectos interessantes que operaram como preâmbulo para as investigações psicanalíticas de Ferenczi (1926/1993), Groddeck (1992, 2004), McDougall (1991 e 1999), Lacan (196263/1985), Marty (1993 e 1997) e Winnicott (1990), dentre outros.
} 
da recapitulação de Haeckel (segundo a qual a ontogenia repete a filogenia). Ou ainda, o fato de que Freud utiliza o termo filogenia para designar as etapas sucessivas da civilização humana, supondo uma única linha de desenvolvimento, quando o termo é mais comumente utilizado para indicar a evolução interespecífica na sucessão das formas do ser vivo. Contudo, são duas as críticas mais contundentes. A primeira se refere à hipótese de que Freud só apelaria para explicações filogenéticas quando sua compreensão através da ontogenia se tornasse lacunar, esbarrando no inexplicável (PERRON, 2005). A segunda aponta para a dificuldade de se perceber em que bases orgânicas a transmissão intergeracional poderia se dar.

Seja como for, especificamente, com relação aos afetos, Freud desenvolvia, no rascunho enviado a Ferenczi (1915d/1976) a mesma ideia tanto de 1893, dos Estudos sobre a histeria, quanto de 1926, do Inibição, sintoma e angústia: os afetos e o modo como são expressos derivam do cruzamento da história dos indivíduos com a história da espécie, da organização psíquica individual com a organização psíquica coletiva, misturando, segundo os termos do próprio metapsicólogo, o que é "constitucional" e o que é "acidental", ou segundo a velha oposição filosófica, a natureza e a cultura (FREUD, 1915d/1976):

\begin{abstract}
"Quando o fator constitucional ou a fixação entram em consideração, a aquisição não [é] assim eliminada; ela só se move para a pré-história ainda mais antiga, porque pode-se justificadamente assumir que as disposições herdadas são resíduos das aquisições de nossos ancestrais. Com isso, entra-se [no] problema da disposição filogenética por trás da individual ou ontogenética, e não se deve encontrar contradição se a individual acrescenta novas disposições de sua própria experiência na sua disposição herdada (adquirida) baseada numa experiência anterior. Porque o processo que cria disposições baseadas na experiência cessaria precisamente no indivíduo cuja neurose se está investigando? Ou (porque deveria) este [indivíduo] criar [uma] disposição para sua progenitura mas não ser capaz de adquiri-la para si mesmo? Mais parecem [ser] necessariamente complementares." (p.10)
\end{abstract}

Em Inibição, sintoma e angústia (1926b/1976), ele afirma que os afetos são "sedimentações de antiquíssimas vivências traumáticas" que, em situações semelhantes, "despertam como uns símbolos mnêmicos" (p.89). Alguns deles chegando mesmo a ser "reproduções de acontecimentos antigos de importância vital, talvez mesmo pré-individuais" (p.126), equiparáveis a "ataques histéricos universais, típicos, congênitos”. Neste texto, Freud (1926b/1976) estava preocupado especificamente com o afeto da angústia e se esforça em demonstrar a pertinência desta concepção. A angústia deve, neste momento, ser compreendida como um 
sinal emitido pelo eu em situações de perigo psíquico ou real, obedecendo à "necessidade biológica” de autopreservação (p.89).

Mais uma vez, Freud recorria ao que aprendera ao longo de sua formação como médico e pesquisador de neurofisiologia e neuroanatomia. Acreditava que as leis que regem o funcionamento corporal encontram correspondentes no funcionamento psíquico. Assim, vinculava o entendimento dos afetos e da gênese do psiquismo em geral à história da espécie humana, apesar de todos os problemas teóricos que decorriam daí. Pois foi justamente nesta "história” da espécie que um outro aspecto de igual importância para a compreensão do psiquismo humano vinha à luz: dentre as inervações motoras que participam dos afetos e de sua expressão, há aquelas que dizem respeito à emissão de sons (a fala, se quisermos). Com isso, alargava sua ideia de hereditariedade: os assim chamados "fatores acidentais", ou seja, a história singular de cada indivíduo e de seus encontros (o que inclui o dito e o não dito, o simbólico), precisavam ser considerados como sendo de algum modo "constitucionais". E vice-versa: o que era constitucional teria sido um dia adquirido. ${ }^{2}$

Como no rascunho enviado a Ferenczi (FREUD, 1915d/1976), Freud (1926b/1976) suavizava a distinção feita pela ciência do começo do século XX entre constituição e acidente, inato e adquirido. O metapsicólogo nunca esqueceu o que alguns estudiosos insistem em classificar como resquício de biologismo decorrente de sua formação positivista: não há alma sem corpo. Entre os dois, ele situou o conceito de afeto: ao mesmo tempo realidade psíquica e realidade material (WINOGRAD, 2002) — o que torna este conceito um instrumento bastante fértil para a abordagem dos fenômenos psicossomáticos entendidos como “sufocamentos do afeto" (MCDOUGALL, 1991, p.152) e relativos a um modo de sofrimento evidenciado no corpo, comprometendo a relação de continuidade psíquico-corporal (FLEMING, 2003), isto é, a unidade psicossomática.

\section{AFETO E FENÔMENO PSICOSSOMÁTICO: PELA INCLUSÃO DO CORPO NA ESCUTA ANALÍTICA}

Na clínica, é preciso considerar que entre o corpo e o psiquismo há zonas de indiscernibilidade (WINOGRAD, 2002), sobretudo ao se lidar com as assim

\footnotetext{
${ }^{2}$ Como destaca Winograd (2007), esta posição freudiana foi alvo de discussões acaloradas. De um lado, estudiosos como Lucille B. Ritvo (1992) defenderam o darwinismo de Freud, afirmando que supô-lo lamarckista é um equívoco, se não um exagero tanto histórico, quanto bibliográfico. Prova disso é a ausência de referências nominais a Lamarck em seus textos publicados em vida. As únicas exceções são um trabalho de 1884 sobre a cocaína e algumas correspondências com Ferenczi, Abraham e Groddeck. Menções suficientemente importantes para levarem autores como Frank J. Sulloway (1979) a considerarem Freud um psico-lamarckista convicto.
} 
chamadas afecções psicossomáticas. Trata-se, nestes casos, de acolher um sofrimento que demanda tanto o reconhecimento dos afetos quanto a consideração da imagem inconsciente do corpo (DOLTO, 1984). Berlinck (2000), no texto Insuficiência imunológica psíquica, chama a atenção, por meio de interessantes metáforas bélicas, para os riscos do desconhecimento do corpo:

\footnotetext{
“Esse desconhecimento (do corpo) é campo fértil para fantasias melancólicas que enfraquecem sobremaneira as defesas a ataques virulentos externos. Fantasias que produzem representações frágeis e pobres do próprio corpo são equivalentes a fantasias maníacas que contém uma concepção onipotente do corpo. Essas fantasias inconscientes que revelam um desconhecimento, uma falta de intimidade com o corpo e, até mesmo, uma recusa do reconhecimento da existência do corpo são, muitas vezes, responsáveis pela insuficiência imunológica a ataques virulentos externos." (p.189-190)
}

Por sua vez, Debray (2001) afirma que "separar nos indivíduos humanos o que atua na cena psíquica do que se vive ao nível do corpo é injustificado. De fato, a antiga dicotomia psique/soma não resiste a esta evidência: somos todos seres psicossomáticos” (p.9).

Contudo, os destinos dos representantes pulsionais (FREUD, 1915c/1976) parecem operar de modo diferenciado na organização psíquica dos sujeitos cuja percepção dos afetos mostra-se precária ou embotada, talvez por resistência às ameaças fantasmáticas do jogo libidinal (FREUD, 1920/1976). Nestes casos, o adoecimento orgânico poderia ser entendido como expressão corporal de afetos não elaborados psiquicamente, ou seja, como somatização regressiva que, através de lesões orgânicas, instauraria uma fronteira tênue entre a vida e a morte. Tais sujeitos se apresentam quase sempre referidos ao registro do corpo orgânico observado e tratado pela abordagem da medicina. Nas sessões de análise, tal corpo se apresenta transferencialmente por meio das queixas, lamentações e narrativas dos périplos médicos percorridos pelo enfermo. Embora tais sujeitos recorram à ciência médica para tentar entender o que acontece ao seu corpo, as queixas apontam para algo que resta e que escapa da apreensão do corpo como organismo, abrindo espaços a outros entendimentos. É este deslocamento da história da doença para a história do doente que a psicanálise deve buscar.

Em seu texto Potências e limites da racionalidade em medicina, Canguilhem (1984) constatou, confrontado ao paradoxo da objetivação do sujeito na medicina psicossomática: "Vejamo-nos aqui tendo chegado ao ponto onde a racionalidade médica se realiza no reconhecimento de seu limite, entendido, não como o fracasso de uma ambição que deu tantas provas de sua legitimidade, mas como a obrigação de mudar de registro" (p.124-125). O filósofo da medicina acreditava que tudo 
o que toca a vida é qualitativo, portanto, é da ordem de uma experiência que a ciência médica não pode anular ao tentar explicar. Mas, se a doença psicossomática interpela os saberes médicos, ela também interroga a psicanálise a partir dos afetos expressos em um corpo que exige escuta e representação.

Dada a primazia do corpo orgânico lesionado, a implicação do sujeito em seu adoecimento mostra-se frágil e, por vezes, inexistente. A acolhida destes sujeitos exige que o analista se posicione tal como propôs Freud em "Sobre o início do tratamento: novas recomendações sobre a técnica da psicanálise I" (1913/1976): “o motor mais direto da terapia é o padecer do paciente e o desejo, que se engendra aí, de ser curado” (p.143). Dito de outro modo, é de interesse do psicanalista interpretar a doença, suas erupções eventuais ou suas recidivas devido a crises, apresentando para o paciente o problema das causas de seu adoecimento, distintas das consideradas pela medicina. Com isso, pretende-se fazer intervir a ideia de uma possível causalidade psíquica e entrelaçar o encontro de duas histórias de alterações de ordem diversa (orgânica e psíquica), cujas relações não são aleatórias.

O sofrimento põe o sujeito face às impotências, limites e decadência orgânicos, expondo-o à perspectiva da morte e precipitando defesas e estratégias de enfrentamento que excedem a dimensão orgânica. A doença, as prescrições e os medicamentos — todo este aparato médico — deve adquirir sentido na dinâmica subjetiva, não dizendo respeito apenas à enfermidade como objeto de investigação biomédica, mas, sobretudo, à sua experiência subjetiva e aos destinos dos afetos em jogo. De modo que entender o pathos (BERLINCK, 2000; FEDIDA, 2001) a partir do que ele apresenta de originário pode ser uma estratégia teórico-clínica interessante para o enfrentamento de pontos de vista que ignoram ser o mal-estar (orgânico) uma manifestação autêntica do sofrimento subjetivo e de suas vicissitudes. Nesse contexto, o conceito de afeto parece constituir um dos pontos centrais da articulação teórica entre psicanálise e medicina quando o sofrimento reside na materialidade do corpo, ou seja, em seu funcionamento orgânico. Porque as manifestações psicossomáticas acometem os sujeitos em sua economia afetiva, exigem alternativas de apreensão teórica e de intervenção clínica que não se limitem à leitura do corpo como organismo.

Diferentemente de um sintoma conversivo, um fenômeno é dito psicossomático quando os sintomas não se inscrevem no corpo histérico (simbólico), mas no corpo médico (orgânico), demandando intervenções, respostas e explicações à fisiopatologia. Contudo, sabemos que a expressão subjetiva também acontece pelo registro orgânico, revelando a necessidade de releitura das expressões afetivas e das marcas deixadas no corpo: o corpo, afetado pelo fenômeno psicossomático, deve ser abordado a partir da dinâmica criadora da sintomatologia que desafia tanto o saber médico quanto o psicanalítico (ÁVILA, 2002). Há um 
sentido neste sintoma? Porque o sujeito adoeceu neste momento e deste jeito? Qual a relação do adoecimento com a sua história? Por outro lado, também os cuidados com a constituição orgânica e com a erogeneidade do corpo significam articulações diversas entre corpo e psiquismo. O corpo orgânico, atingido na sua materialidade tecidual e humoral, corresponde a um modo de relação corpo-psiquismo que pode levar à morte. É que, de maneira diversa do corpo do neurótico, no fenômeno psicossomático o corpo afetado não seria apenas, por exemplo, o representado na anatomia fantasmática da histeria de conversão. Os sintomas psicossomáticos não corresponderiam nem à comunicação neurótica nem à restituição psicótica, mas, sim à expressão dos afetos por meio de, por exemplo, simbolizações viscerais (VALABREGA, 1954).

Embora não tenha se preocupado mais detidamente com as questões psicossomáticas, Freud escreveu em 1923: "E segundo o indicam alguns analistas, o tratamento analítico de graves enfermidades orgânicas tampouco deixa de ser promissor, pois, não raro, um fator psíquico participa da gênese e da duração destas afecções" (1923/1976, p.246). Mesmo tendo enfatizado sua descrença na aplicabilidade da terapia psicanalítica a todos os casos, Freud (1895a/1976) destacou que pacientes sob tratamento médico em hospitais poderiam se beneficiar da ajuda de métodos complementares, tais como a psicoterapia psicanalítica, a qual vinha se mostrando eficaz no tratamento de casos severos de histeria e neurose obsessiva.

Nos anos finais do século XIX, Freud (1893/1976, 1894/1976 e 1895a/1976) dedicou diversos escritos à discussão da etiologia das neuroses, destacando didaticamente aspectos específicos às psiconeuroses e à neurastenia, neurose de angústia e hipocondria. No entanto, ele sempre demonstrou preocupação em ressaltar os pontos em comum nas sintomatologias dessas doenças, enfatizando as possíveis organizações mistas, as misturas de neuroses. O diagnóstico constituía um momento que exigia cautela para Freud (1895a/1976). Como ilustração, citamos um fragmento de Sobre os critérios para destacar da neurastenia uma síndrome particular intitulada neurose de angústia, no qual Freud (1895a/1976) expõe que a neurose de angústia seria

“(...) o correspondente somático da histeria. Aqui como lá, acúmulo de excitação (no qual tenha, talvez, fundamento a semelhança já descrita entre os sintomas); aqui como lá, uma insuficiência psíquica que produz, como consequência, processos somáticos anormais. Aqui como lá, ao invés de um processamento psíquico, intervém um desvio da excitação até o somático; a diferença reside meramente em que a excitação, cujo deslocamento (descentramento) se exterioriza na neurose, é puramente somática na neurose de angústia (excitação sexual somática), enquanto que, na histeria, é psíquica (provocada por um conflito)." (p.114) 
O fundador da psicanálise, desde cedo, assumiu as dificuldades em tratar doenças orgânicas, admirando Ferenczi quando esse se atirava nas águas turvas do adoecimento somático desafiador das elaborações sobre as conversões e a hipocondria. Ferenczi (1926/1993) escreve que "foi necessário esperar o advento do método psicanalítico introduzido por Freud para se poder explicar, até uma profundidade antes insuspeitada, a vida pulsional onde o corpo e o psiquismo não param de influenciar-se mutuamente" (p.381). De fato, histeria e hipocondria aproximaram a psicanálise do fenômeno psicossomático, defrontando-a com desafios que não eram facilmente convocados à palavra, à expressão da vida onírica e fantasmática, à elaboração dos trabalhos de luto, enfim, à montagem de uma história nos moldes de um romance familiar (FREUD, 1909/1976). É que o fenômeno psicossomático exige a consideração do sujeito em seu adoecimento para que tenha lugar a construção de ressignificações do adoecer orgânico.

Influenciado por estas ideias, Franz Alexander (1962) discute com Dunbar (1910-1953/1976) a respeito das hipóteses de que a patologia orgânica teria relação com perfis de personalidade pré-mórbidos específicos para certos quadros clínicos: a estrutura da personalidade tornaria uma parte determinada do organismo frágil e vulnerável à agressão externa, o que preparia o solo para somatizações. Para Alexander (1962), a hipótese de um perfil de personalidade como causa seria insuficiente. Ao invés, seria necessário considerar o que ele chama de constelação psicodinâmica específica, ou seja, reações de base derivadas de um estado de tensão do aparelho psíquico, englobando o sistema neurovegetativo, o eixo subcortical e os dados humorais. Embora sujeito a críticas, Alexander (idem) deu lugar de destaque aos conflitos psíquicos e aos afetos culminando em modificações corporais. Suas ideias fizeram-no retomar a noção ferencziana de "neurose de órgão", relativa à hipótese da estagnação anormal de uma quantidade de energia em um órgão ou um aparelho. Tais ligações entre estados afetivos e comportamentos somáticos produziriam padrões somáticos que poderiam se manifestar como distúrbios funcionais redundando em sintomas orgânicos.

Por volta dos anos 1960, na França, outra abordagem das doenças psicossomáticas ganhou destaque, modificando ou ampliando algumas hipóteses e transformando a abordagem clínica. Valabrega abordava o sintoma somático entendendo-o como um fenômeno de conversão generalizada cuja fonte fantasmática, ao ser reencontrada, lhe daria um sentido. Desnecessário apontar o lugar central do conceito de afeto nesta formulação: divorciado da representação (fantasia, fantasma), o afeto se desloca para o corpo em um movimento conversivo, alimentando simbolizações manifestamente viscerais (VALABREGA, 1954). Neste contexto teórico da conversão psicossomática, o sintoma constituiria uma espécie de barreira corporal a ser transposta pela recondução dos afetos às representações 
fantasmáticas latentes e, como consequência, da desconstrução de tais elementos. Assim, a conversão psicossomática confundir-se-ia com a conversão histérica teorização passível de críticas sobre as quais não nos deteremos aqui.

Neste mesmo período (1960), outra abordagem das doenças psicossomáticas era formalizada na França, e ficou conhecida como Escola Psicossomática de Paris, tendo em Marty (1993) um de seus representantes mais célebres. Correndo o risco de uma simplificação excessiva, podemos afirmar que as formulações desta escola operam com as ideias básicas de déficit, carência psíquica (fantasmática, onírica, associativa, de defesas etc.). Deste ponto de vista, o sintoma psicossomático seria assimbólico. Marty avança a noção de pensamento operatório, identificando figuras clínicas como a "depressão essencial" e a "desorganização crônica" e insistindo na ideia de que o dispositivo de regressão e de fixação teriam valor reorganizador. Nos processos de somatização, o trauma faria avançar a desorganização, mas não chegaria a suspender o que ele chama de sistema de regressão/fixação (MARTY, 1993).

Ao mesmo tempo próxima e distante de Marty, McDougall (1992) propõe ser o corpo a maneira mais ecônomica de reviver os traumatismos, insistindo na economia do afeto e nas possibilidades de acomodá-la como for possível. Dentre tais possibilidades, a autora sublinha que, na ausência de toda atividade metafórica, o corpo seria a única expressão possível dos afetos assim separados de seu papel psíquico. Ao comentar o trabalho de McDougall (1992), Caïn (2000) sublinha o agir corporal enquanto sistema de defesa atual, como único modo de expressão anterior à palavra.

A clínica psicanalítica das doenças orgânicas seria, então e antes de tudo, uma clínica dos afetos, lugar de reinvenção de um sujeito atado às amarras de seu corpo afetado. Afinal, onde mais os afetos poderiam ser sentidos e experimentados, se não no corpo? A construção do setting terapêutico se daria, então, a partir do reconhecimento de que afetos são expressos no e pelo corpo, rompendo seu equilíbrio: trata-se de um saber inscrito no corpo e que resiste a ser confrontado com a dúvida, com o contraditório e com o afetivo no discurso. Dito de outro modo, a clínica dos fenômenos psicossomáticos mostraria os efeitos do que extrapola os objetivos vitais, evidenciando a clivagem do sujeito, os destinos dos afetos, a angústia e as possibilidades de construção de sentido. Vale apontar que, na atual clínica psicanalítica das doenças psicossomáticas, diferentemente do quadro nosológico em que Freud situou as neuroses atuais (precursoras das psicopatologias somáticas), as relações precoces e os momentos primitivos de constituição do eu têm merecido destaque (DOUCET, 2000, FADDEN, 2000, VOLICH, 2000). Seja como for, de modo geral, não é arriscado afirmar que o trabalho clínico visa permitir que o sujeito se posicione frente à doença sem experimentar a autocensura melancólica de aspecto regressivo, expressa na 
dor relativa à iminência de sua destruição como sujeito, e reconstrua sua rede simbólica pela inclusão do corpo biológico, elaborando os afetos na construção de uma história.

\section{CONSIDERAÇÕES FINAIS}

A investigação das psicopatologias somáticas impõe-se como tema de interesse para a clínica, exigindo reelaborações metapsicológicas que contemplem os lugares do corpo e dos afetos. Com a ênfase da psicanálise no recalque, a problemática do afeto parece ter ficado em um plano pouco iluminado pelas teorizações, causando uma lacuna muitas vezes comprometedora dos rumos dos atos clínicos (BIRMAN, 2006). Resgatar as elaborações freudianas acerca do conceito e dos destinos do afeto, especialmente a supressão (FREUD, 1915a/1976), pode abrir espaço para a escuta da dor dos corpos enfermos. Não se pode esquecer que a ruptura epistemológica que inaugura a clínica freudiana é herdeira da linhagem filosófica na qual corpo e psiquismo não são substâncias distintas, mas compõem uma unidade que pode ser denominada de psicossomática.

É esse corte com a cultura da anatomopatologia que instaura a possibilidade de uma clínica da escuta, segundo Berlinck (2000), predominantemente visual, já que ocorre no âmbito das transferências que produzem, de início, afetos e imagens. Tratamos, neste breve ensaio, da metapsicologia do afeto e dos destinos do corpo nas formações psicossomáticas, tema de relevância, em especial quando os processos de subjetividade hegemônicos na atualidade interrogam o estatuto do corpo na sua singularidade, extravagância e desmesura, sendo este submetido às eficientes tecnologias de medicalização da dor e das variações de humor - enfim, do sofrimento psíquico.

\section{REFERÊNCIAS}

ALEXANDER, F. (1962) La médecine psychossomatique. Paris: Payot. ASSOUN, P.-L. (1997) Psychanalyse. Paris: PUF.

ÁVILA, A. L. (2002) Doenças do corpo e doenças da alma. São Paulo: Escuta. BERLINCK, M. T. (2000) Psicopatologia fundamental. São Paulo: Escuta.

BIRMAN, J. (1999) Mal-estar na atualidade. São Paulo: Civilização Brasileira.

(2006) Arquivos do mal-estar e da resistência. São Paulo: Civilização Brasileira.

CANGUILHEM, G. (1984) Puissance et limites de la rationalité em médecine, in MARX, C. (Org.). Médecine, science et technique. Paris: Éditions du CNRS. 
CAÏN, J. (2000) Contratransferência e psicossomática, in McDOUGALL, J. GACHELIN, G., AULAGNIER, P., MARTY, P., LORIOD, J. \& CAÏN, J. (2000). Corpo e história - IV encontro psicanalítico d'Aix-en-Provence - 1985. São Paulo: Casa do Psicólogo.

COSTA, J.F. (2004) O vestígio e a aura: corpo e consumismo na moral do espetáculo. Rio de Janeiro: Garamond.

DEBRAY, R. (2001) Épître à ceux qui somatisent. Paris: PUF.

DEJOURS, C. (1994) Repressão e subversão em psicossomática: pesquisas psicanalíticas sobre o corpo. Rio de Janeiro: Jorge Zahar Editor.

DOLTO, F. (1984) L’image inconsciente du corps. Paris: Éditions du Seuil.

DOUCET, C. (2000) La psychosomatique: théorie et clinique. Paris: Armand Colin.

DUNBAR, H. (1910-1953/1976) Emotions and bodily changes: a survey of literature on psychosomatic interrelationships, 1910-1953. Nova York: Ayer Company Publisher.

FADDEN, M.A. (2000) Psicanálise e psicossomática. São Paulo: Alínea.

FÉDIDA, P. (2001) Des bienfaits de la dépression: éloge de la psychothérapie. Paris: Odile Jacob.

FERENCZI, S. (1926/1993) As neuroses de órgão e seu tratamento, in Psicanálise III. São Paulo: Martins Fontes.

FLEMING, M. (2003) Dor sem nome. Pensar o sofrimento. Porto, PT: Afrontamento.

FREUD, S. (1976) Sigmund Freud — Obras completas. Buenos Aires: Amorrortu Editores.

(1893-1895) "Estudios sobre la histeria”, v. II, p.27-310.

(1894) “Las neuropsicosis de defensa”, v. III, p.41-68.

(1895a) "Sobre la justificación de separar de la neurastenia um determinado síndrome em calidade de 'neurosis de angustia”, v. III, p.85-116.

(1895b) “Proyecto de psicología”, v. I, p.323-436.

(1896) "Nuevas puntualizaciones sobre las neuropsicosis de defensa. v. III, p.157-184.

(1898) “La sexualidad em la etiología de las neurosis". v. III, p.251-276.

(1900) “La interpretación de los sueños”, v. IV e V, p.1-612.

(1909) "La novela familiar de os neuróticos", v. IX, p.213-220.

(1913) "Sobre la iniciación del tratamiento (Nuevos consejos sobre la técnica del psicoanáisis, I)”, v. XII, 121-144.

(1914) “Introducción del narcisismo”, v. XIV, p.65-98.

(1915a) "Lo inconciente", v. XIV, p.153-214.

(1915b) “La repressión”, v. XIV, p.135-152.

(1915c) “Pulsiones y destinos de pulsión”, v. XIV, p.105-134

(1915d/1976) A phylogenetic fantasy - overview of the transference neuroses. Londres: The Belknap Press, 1987.

(1916-17) “Conferencias de introducción al psicoanálisis”, v. XV e XVI, p.1-440.

(1917) “Duelo y melancolia”, v. XIV, p.235-256.

(1918/1976) "De la historia de una neurosis infantil”, A. E., v. XVII.

(1920) “Más allá del principio de placer”, v. XVIII, p.1-62. 
(1921) “Psicologia de las masas y análisis del yo”, v. XVIII, p.63-136. (1923/1976) Dos artículos de enciclopedia: "Psicoanálisis" y “Teoría de la libido". A. E., v. XVIII.

(1926a) “El problema económico del masoquismo”, v. XIX, p.161-178.

(1926b) “Inhibición, síntoma y angustia”, v. XX, p.71-161.

GREEN, A. (1997) “Concept(s) limite(s): singulier ou pluriel?”, in SCHMID-KITSIKIS, E. \& SANZANA, A. (Orgs.) Concepts limites en Psychanalyse. Paris: Delachaux et Niestlé.

GRODDECK, G. (1992) Estudos psicanalíticos sobre psicossomática. São Paulo: Perspectiva.

. (2004) O livro d'Isso. São Paulo: Perspectiva.

KERNBERG, O. (1995) Agressão nos transtornos de personalidade e nas perversões. Porto Alegre: Artmed.

LACAN, J. (1962-63/1985) O Seminário. Livro 2. O eu na teoria de Freud e na técnica da psicanálise. Rio de Janeiro: Jorge Zahar.

LAPlANCHE, J. \& PONTALIS, J-B. (1986) Vocabulário da psicanálise. São Paulo: Martins Fontes.

MARTY, P. (1993) A psicossomática do adulto. Porto Alegre: Artes Médicas.

MCDOUGALL \& J MARTY, P. (1997) Mentalização e psicossomática. São Paulo: Casa do Psicólogo.

MCDOUGALL, J. (1991) Em defesa de uma certa anormalidade. Teoria e clínica psicanalíticas. Porto Alegre: Artes Médicas. (1992) Teatros do Eu. Rio de Janeiro: Francisco Alves.

(1999) Teatros do corpo: o psicossoma em psicanálise. Rio de Janeiro: Martins Fontes.

NASIO, J. D. (1997) O livro da dor e do amor. Rio de Janeiro: Jorge Zahar Editor. Zahar.

(2000) Psicossomática: as formações do objeto a. Rio de Janeiro: Jorge

PERRON, R. (2005) Verbete ‘filogenia'. In: MIJOLLA, A. (2005) Dicionário internacional da psicanálise. Rio de Janeiro: Imago.

REYS, B. (1998) O problema do afeto em Freud e Lacan. Dissertação de mestrado/ IP/UFRJ. (mimeo)

RITVO, L. (1992) A influência de Darwin sobre Freud, Rio de Janeiro: Imago.

SULLOWAY, F. J. (1979) Freud, biologist of the mind, Cambridge: Harvard University Press.

VALABREGA, J-P.(1954) Les théories psychosomatiques. Paris: PUF.

VOLICH, R. M. (2000) Psicossomática. São Paulo: Casa do Psicólogo.

WINNICOTT, D. W. (1990) A natureza humana. Rio de Janeiro: Imago.

WINOGRAD, M. (2002). Freud, o Corpo e o Psiquismo. Percurso. Revista de Psicanálise, v. 28, p. 49-54, 2002

(2007) Freud e a filogenia anímica. Revista do Departamento de Psicologia — UFF, v. 19, n. 1, p.69-82, jan-jun, 2007.

Monah Winograd

winograd@uol.com.br 